\title{
Effect of STC2 gene silencing on colorectal cancer cells
}

\author{
QIANYUAN LI, XIUKOU ZHOU, ZHENGYU FANG and ZHIYUN PAN \\ Department of Anorectal Surgery, The First Affiliated Hospital of Zhejiang Chinese Medical University, \\ Hangzhou, Zhejiang 310006, P.R. China
}

Received October 9, 2018; Accepted March 27, 2019

DOI: $10.3892 / \mathrm{mmr} .2019 .10332$

\begin{abstract}
Stanniocalcin 2 (STC2), a secretory glycoprotein hormone, regulates many biological processes including cell proliferation, apoptosis, tumorigenesis and atherosclerosis. However, the effect of STC2 on proliferation, migration and epithelial-mesenchymal transition (EMT) progression in human colorectal cancer (CRC) cells remains poorly understood. The expression level of STC2 was determined by quantitative real-time polymerase chain reaction (qPCR) and western blot analysis. Cell Counting Kit-8 (CCK-8) was used to detect the viability of SW480 cells. The invasion and migration of cells were identified by wound healing and Transwell assays. The mRNA and protein expression levels of $\beta$-catenin, matrix metalloproteinase (MMP)-2, MMP-9, E-cadherin and vimentin were assessed by qPCR and western blot analysis. In the present study, it was demonstrated that $S T C 2$ was highly expressed in the CRC cell lines. After silencing of STC2, the cell viability, migration and invasion were significantly reduced. Silencing of STC2 in the CRC Sw480 cells increased the expression of E-cadherin and decreased the expression of vimentin, MMP-2 and MMP-9, compared to those in the normal and empty vector group. Furthermore, the expression of $\beta$-catenin in the STC2 gene silenced group was suppressed, and the expression of $\beta$-catenin was reversed by Wnt activator, SB216763. These results demonstrated that STC2 participates in the development and progression of CRC by promoting CRC cell proliferation, survival and migration and activating the $\mathrm{Wnt} / \beta$-catenin signaling pathway.
\end{abstract}

\section{Introduction}

According to data released by GLOBOCAN in 2012, the incidence of colorectal cancer (CRC) was the third highest in regards to all male malignant tumors and the second highest

Correspondence to: Dr Zhiyun Pan, Department of Anorectal Surgery, The First Affiliated Hospital of Zhejiang Chinese Medical University, 54 Youdian Road, Shangcheng, Hangzhou, Zhejiang 310006, P.R. China

E-mail: pzhiyun_zypan@163.com

Key words: STC2, stanniocalcin 2, colorectal cancer cells, EMT, $\mathrm{Wnt} / \beta$-catenin in regards to female malignant tumors (1). Studies have shown that the progression of CRC is a multi-stage, multi-factor process (1-3). Effective inhibition of CRC metastasis is a major clinical issue. It has been found that the invasion and migration of tumors are closely related to epithelial-mesenchymal transition (EMT) (4).

EMT refers to the phenomenon that epithelial cells switch to mesenchymal cells under specific pathological conditions (4). During the evolution of tumor growth, EMT mainly includes changes in reconstruction of the cytoskeleton, cell polarity, loss of adhesion between cells, destruction of the tumor basement membrane and extracellular matrix, resulting in high migration and invasion capacity, anti-apoptosis and degradation of interstitial phenotypic characteristics such as the extracellular matrix (5). Studies have shown that matrix metalloproteinase (MMP) family genes, especially $M M P-2$ and $M M P-9$, can alter the microenvironment of epithelial cells by remodeling of the matrix membrane and extracellular matrix, downregulating E-cadherin expression, upregulating vimentin expression and promoting EMT progression (6). This process is usually triggered by a variety of growth factors (such as epidermal growth factor) to activate the cascade of signal transduction pathways such as Wnt, resulting in enhanced anti-apoptotic and invasive capacities of tumor-initiating cells, ultimately leading to tumor development (7-9).

One of the most important signaling pathways for regulating EMT is the $\beta$-catenin-dependent classical Wnt signaling pathway (10). $\beta$-catenin is an intercellular adhesion molecule, mainly located in the cell membrane, which mediates intercellular adhesion and participates in gene expression. However, the adhesion activity will disappear once $\beta$-catenin is translocated to the cell nucleus or degraded (11). Overexpression of $\beta$-catenin is also a major manifestation of activation of signaling pathways (12). $\beta$-catenin is a key regulator of the Wnt/ $\beta$-catenin signaling pathway. Wnt proteins bind to their receptors, which trigger intracellular signal transduction, and lead to $\beta$-catenin accumulation within the cell which translocates into the nucleus and interacts with transcription factors (such as TCF) to activate the transcription of the target genes such as $c$-Myc and cyclin Dl $(13,14)$. Research has confirmed that the Wnt signaling pathway activates genes related to the MMP family and leads to the development of EMT (15).

Stanniocalcin 2 (STC2) is a secreted glycoprotein that is expressed in a variety of tissues and organs and functions in an autocrine or paracrine manner (16). Recent experiments have shown that STC2 plays an important role in the development 
of cancer including CRC $(17,18)$. However, to the best of our knowledge, whether or not STC2 regulates the Wnt signaling pathway in CRC has not yet been studied. In the present study, CRC cell line SW480 was used as the main research tool to investigate whether or not the effect of STC2 on CRC proliferation, migration and EMT is related to the Wnt signaling pathway.

\section{Materials and methods}

Reagents. Human CRC cell lines (SW480, SW620, HT29, LoVo and HCT116) and human normal colorectal mucosal FHC cells were obtained from the American Type Culture Collection (ATCC; Rockville, MD, USA). SB216763 was purchased from Sigma-Aldrich (280744-09-4; HPLC >98\%; Merck KGaA, Darmstadt, Germany). CCK-8 assay kit was obtained from Nanjing Jiancheng Bioengineering Institute (Nanjing, China). Transfection reagent Lipofectamine ${ }^{\circledR} 3000$ was purchased from Invitrogen (Thermo Fisher Scientific, Inc., Waltham, MA, USA).

Cell culture and transfection. Human CRC cell lines (SW480, SW620, HT29, LoVo and HCT116) and human normal colorectal mucosal cells (FHC) were cultured in RPMI-1640 medium (Invitrogen; Thermo Fisher Scientific, Inc.) containing $10 \%(\mathrm{v} / \mathrm{v})$ fetal bovine serum (FBS; Invitrogen; Thermo Fisher Scientific, Inc.) at $37^{\circ} \mathrm{C}$ in a humidified atmosphere with $5 \% \mathrm{CO}_{2}$. The non-specific control small interference RNA (siRNA) and siSTC2 were obtained from Shanghai GenePharma Co., Ltd. (Shanghai, China). The siSTC2 was inserted into the pSUPER vector (OligoEngine, Inc., Seattle, WA, USA), and the empty pSUPER vector was used as a negative control. Lipofectamine ${ }^{\circledR}$ (LFN) transfection (Thermo Fisher Scientific, Inc.) was performed according to the manufacturer's instructions. In brief, the lipid complex was prepared by combining $4 \mu \mathrm{l}$ of the reagent LFN Plus with $2 \mu \mathrm{g}$ of plasmid DNA suspended in $1 \mathrm{ml}$ serum-free medium and incubated at room temperature for $15 \mathrm{~min}$. The solution was then mixed with $40 \mu \mathrm{l}$ of LFN in serum-free medium and further incubated at room temperature for $15 \mathrm{~min}$. Lipid compounds will first be diluted in serum-free medium to produce a required concentration for $5 \mathrm{ml}$ volume, and then incubated with the cells in an incubator with $5 \% \mathrm{CO}_{2}$ at $37^{\circ} \mathrm{C}$ under $24 \mathrm{~h}$ for subsequent experimentation.

Cell viability assay. Having transferred the SW480 cells at $0,12,24$ and $48 \mathrm{~h}$ post-culture, $10 \mu \mathrm{l}$ of CCK- 8 solution was added into the wells and the cells were incubated at $37^{\circ} \mathrm{C}$ for $2 \mathrm{~h}$ in an incubator with $5 \% \mathrm{CO}_{2}$ in the dark. Subsequently, the optical density (OD) of each well in the different cell groups at an absorbance of $450 \mathrm{~nm}$ was determined using a microplate reader (Bio-Rad Laboratories, Inc., Hercules, CA, USA). Cell viability was detected using the CCK-8 assay kit according to the manufacturer's protocol.

Wound healing assay. Having transferred the SW480 cells for $24 \mathrm{~h}$, a straight gap was created using a 200- $\mu$ l sterile tip in the middle of the well. The cells were washed with Dulbecco's modified Eagle's medium (DMEM) for 2 times for smoothing the edges of the scratch and removing floating cells. After being incubated in an incubator $\left(37^{\circ} \mathrm{C}, 5 \% \mathrm{CO}_{2}\right)$ for 0 and $24 \mathrm{~h}$, the images of the migrating cells were observed under a digital microscope (Keyence Corp., Osaka, Japan), and the distance of cell migration was measured by Image-Pro Plus Analysis software version 7 (Media Cybernetics, Inc., Rockville, MD, USA). The experiment was repeated 3 times and the results are presented using mean values.

Transwell assay. A Transwell chamber with $8-\mu \mathrm{m}$ pores (3413; Corning Inc., Corning, NY, USA) was placed on a 24-well plate with a layer of $50 \mu 1$ Matrigel (BD Biosciences, Franklin Lakes, NJ, USA) coated onto the Transwell chamber. The SW480 cells were cultured in serum-free medium for $12 \mathrm{~h}$ to eliminate the effects of the serum and then resuspended in DMEM containing bovine serum albumin (BSA; Sigma-Aldrich; Merck KGaA) with free FBS. A total of $100 \mu 1$ of the suspended cells was added to the Transwell chamber, and $400 \mu \mathrm{l}$ of DMEM containing $20 \%$ FBS was added to the basolateral chamber. The cells were cultured for $24 \mathrm{~h}$ at $37^{\circ} \mathrm{C}$ in an incubator with $5 \% \mathrm{CO}_{2}$. The Transwell chamber was removed and the culture solution in the Transwell was discarded and washed with calcium-free phosphate-buffered saline (PBS) for 2 times. Subsequently, the chamber was fixed in methanol solution for $30 \mathrm{~min}$ and stained with $0.1 \%$ crystal violet for $20 \mathrm{~min}$ at room temperature. Next, the chamber was washed several times with PBS, and the upper chamber liquid was aspirated. The non-migratory cells in the upper layer were gently wiped off using a cotton swab. The microporous membrane was carefully removed using small tweezers, dried with the bottom side up and then transferred to a glass slide and sealed using a neutral gum. Images were observed and collected by an inverted optical microscope (Keyence Corp.).

Western blot analysis. The SW480 cells were washed twice with PBS and added to protein lysis buffer (RIPA; Cell Signaling Technology, Inc., Danvers, MA, USA) for $2 \mathrm{~h}$ on ice, centrifuged at $12,000 \mathrm{x} \mathrm{g}$ for $30 \mathrm{~min}$ at $4^{\circ} \mathrm{C}$, and finally the supernatant was collected. The protein concentration was tested using the BCA protein kit (Bio-Rad Laboratories) and adjusted to a concentration of $5 \mu \mathrm{g} / \mu \mathrm{l}$ using $1 \mathrm{X}$ loading and diethylpyrocarbonate (DEPC) water. A total of $6 \mu \mathrm{l}$ (at least $30 \mu \mathrm{g}$ ) of the samples were electrophoresed $(80 \mathrm{~V}$ for $30 \mathrm{~min}$ and then transferred to $120 \mathrm{~V}$ for $1.5 \mathrm{~h}$ ) on $10 \%$ running gels, which afterwards, was transferred to polyvinylidene fluoride (PVDF) membranes (Bio-Rad Laboratories) on ice for $110 \mathrm{~min}$ at $110 \mathrm{~V}$. The membranes were blocked with 5\% non-fat milk and eluted 3 times with TBS for $5 \mathrm{~min}$ each time. The bands were then incubated overnight with the corresponding primary antibody, washed with TBS 3 times for 15 min, incubated with secondary antibodies [horseradish peroxidase (HRP)-conjugated goat anti-mouse/rabbit IgG (dilution 1:2,000; cat. nos. sc-516102 and sc-2357; Santa Cruz Biotechnology, Inc. Dallas, TX, USA)] for $2 \mathrm{~h}$ at room temperature, washed with TBS 3 times for $15 \mathrm{~min}$ each time, and furthermore washed once with TBS/0.1\% Tween-20 (TBST) for $15 \mathrm{~min}$. Development was carried out with a developer (EZ-ECL kit; Biological Industries Ltd., Kibbutz Beit Haemek, Israel), and the gray-scale value of the strips were analyzed and determined by ImageJ (version 5.0; Bio-Rad Laboratories). The antibodies used in the present study were as follows: Anti-GAPDH (mouse; 
Table I. Primers for qPCR.

\begin{tabular}{lll}
\hline Genes & \multicolumn{1}{c}{ Forward } & \multicolumn{1}{c}{ Reverse } \\
\hline STC2 & 5'-ATGCTACCTCAAGCACGACC-3' & 5'-TCTGCTCACACTGAACC TGC-3' \\
E-cadherin & 5'-AAGGCACAGCCTGTCGAAGCA-3' & 5'-ACGTTGTCCCGGGTGTCATCCT-3' \\
Vimentin & 5'-TGCCCTTAAAGGAACCAATGAG-3' & 5'-AGGCGGCCAATAGTGTCTTG-3' \\
MMP-2 & 5'-AGTTTCCATTCCGCTTCCAG-3' & 5'-CGGTCGTAGTCCTCAGTGGT-3' \\
MMP-9 & 5'-GTCCACCCTTGTGCTCTTCC-3' & 5'-GACTCTCCACGCATCTCTGC-3' \\
$\beta$-catenin & 5'-ATGCGGCTGCTGTTCTATTC-3' & 5'-ACCAATGTCCAGTCCGAGAT-3' \\
GAPDH & 5'-ACTTTGGTATCGTGGAAGGACTCAT-3' & 5'-GTTTTCTAGACGGCAGGTCAGG-3'
\end{tabular}

qPCR, quantitative PCR; STC2, stanniocalcin 2.

dilution 1:1,000; cat. no. sc-47724; Santa Cruz Biotechnology), anti-STC2 (rabbit; dilution 1:1,000; cat. no. ab63057; Abcam, Cambridge, MA, USA), anti-E-cadherin (mouse; 1:1,000; ab1416; Abcam), anti-vimentin (rabbit; dilution 1:1,000; cat. no. ab92547; Abcam), anti-MMP-2 (rabbit; dilution 1:1,000; cat. no. ab37150; Abcam), anti-MMP-9 (rabbit; dilution 1:1,000; cat. no. ab73734; Abcam).

RNA isolation and real-time PCR. The cell culture medium in each well was aspirated as much as possible, and $1 \mathrm{ml}$ of TRIzol (Invitrogen; Thermo Fisher Scientific, Inc.) was added to the SW480 cells. The cells were placed horizontally for a while and blown evenly. The cells containing the lysate were transferred to a 1.5-ml EP tube and allowed to stand at room temperature for $5 \mathrm{~min}$. Chloroform $(200 \mu \mathrm{l})$ was added to each tube and inverted for $15 \mathrm{sec}$. After emulsification, the cells were allowed to stand for $5 \mathrm{~min}$. After being centrifuged at $12,000 \mathrm{x} \mathrm{g}$ for $15 \mathrm{~min}$ at $4^{\circ} \mathrm{C}$, the upper aqueous phase was pipetted into a new $1.5 \mathrm{ml}$ of EP and an equal volume of isopropanol $(\sim 400 \mu \mathrm{l})$ was added to each tube and allowed to stay at room temperature for $10 \mathrm{~min}$. After being centrifuged at $12,000 \mathrm{x}$ g for $15 \mathrm{~min}$ at $4^{\circ} \mathrm{C}$, the supernatant was discarded and $1 \mathrm{ml}$ of pre-cooled $75 \%$ ice ethanol was added. After being centrifuged at 7,500 x g for $10 \mathrm{~min}$ at $4^{\circ} \mathrm{C}$, the supernatant was discarded. An appropriate amount of DEPC $(20 \mu \mathrm{l})$ was added to dissolve the RNA. The purity and concentration of RNA were tested at 260/280 $\mathrm{nm}$ using the NanoDrop ND-1000 spectrophotometer (NanoDrop Technologies; Thermo Fisher Scientific, Inc.). According to the program provided by the manufacturer (Thermo Fisher Scientific, Inc.), a reverse transcription cDNA kit was used to reverse transcribe $1 \mu \mathrm{g}$ total RNA for synthesis of cDNA (at $42^{\circ} \mathrm{C}$ for $60 \mathrm{~min}$, at $70^{\circ} \mathrm{C}$ for $5 \mathrm{~min}$, at $4^{\circ} \mathrm{C}$ for preservation). SYBR-Green PCR Master Mix (Roche Diagnostics, Basel, Switzerland) was used to perform quantitative real-time polymerase chain reaction (qPCR) experiment using Opticon Real-Time PCR Detection System (ABI 7500; Life Technologies; Thermo Fisher Scientific, Inc.). The PCR cycle was as follows: Pretreatment at $95^{\circ} \mathrm{C}$ for $10 \mathrm{~min}$; followed by 40 cycles at $94^{\circ} \mathrm{C}$ for $15 \mathrm{sec}$, at $60^{\circ} \mathrm{C}$ for $1 \mathrm{~min}$, finally at $60^{\circ} \mathrm{C}$ for $1 \mathrm{~min}$ and at $4^{\circ} \mathrm{C}$ for preservation. The relative mRNA quantity was determined using comparative cycle threshold ( $\Delta \Delta \mathrm{Cq})$ method (19). GAPDH expression was used for normalization. The primer sequences used for RT-qPCR analysis are listed in Table I.
Statistical analyses. Data are presented as the means \pm standard deviation (SD). Differences between the multiple groups were assessed by one-way analysis of variance (ANOVA) followed by Dunnett's post hoc test. Differences were analyzed by GraphPad Prism 6 (GraphPad Software, Inc., La Jolla, CA, USA) and all comparisons with a $\mathrm{P}<0.05$ were considered statistically significant.

\section{Results}

STC2 is highly expressed in CRC cell lines. To select a suitable CRC cell line, qPCR (Fig. 1A) and western blot analysis (Fig. 1B) were performed to analyze the expression level of STC2 in the cell lines. We discovered that STC2 was highly expressed in CRC cell lines (SW480, SW620, HT29, LoVo and HCT116), particularly in SW480 cells. Thus, SW480 cells were selected for subsequent experiments.

Viability, invasion and migration potentials of the CRC cells are suppressed by siSTC2. In the present study, the efficiency of siSTC2 transfection was confirmed by qPCR and western blot analysis. We found that STC2 was silenced by plasmid transfection (Fig. 2A and B). Subsequently, we examined the viability, invasion and migration of the cells after plasmid transfection, and found that the cell viability was lower in the siSTC2 group than that in the control or NC group after 24 and $48 \mathrm{~h}$ of plasmid transfection (Fig. 2C), and that the abilities of migration (Fig. 2D) and invasion (Fig. 2E) were decreased in the siSTC2 group, compared to the control or $\mathrm{NC}$ group. The wound closure gap in the siSTC2 group was significantly wider than that in the control and $\mathrm{NC}$ group at $24 \mathrm{~h}$ indicating reduced migration ability (Fig. 2F). As shown in Fig. 2G, the rate of invasion in the siSTC2 group was significantly lower than that in the control and NC group.

siSTC2 downregulates the expression of vimentin, MMP-2 and $M M P-9$ and upregulates the expression of E-cadherin in CRC cells. It has been reported that EMT is an important marker of CRC development (20). The results showed a significant increase in the expression of E-cadherin (Fig. 3A) and a reduction in the expressions of vimentin (Fig. 3B), $M M P-2$ (Fig. 3C) and MMP-9 (Fig. 3D) in the SW480 cells following silencing of STC2. The protein level of E-cadherin (Fig. 3E) was upregulated and vimentin (Fig. 3E), MMP-2 (Fig. 3E) and 
A

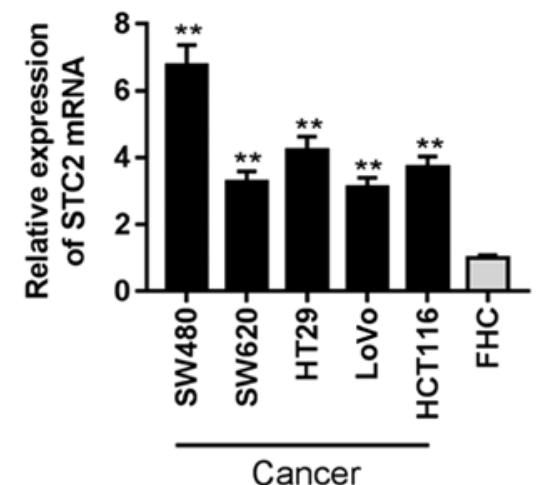

B
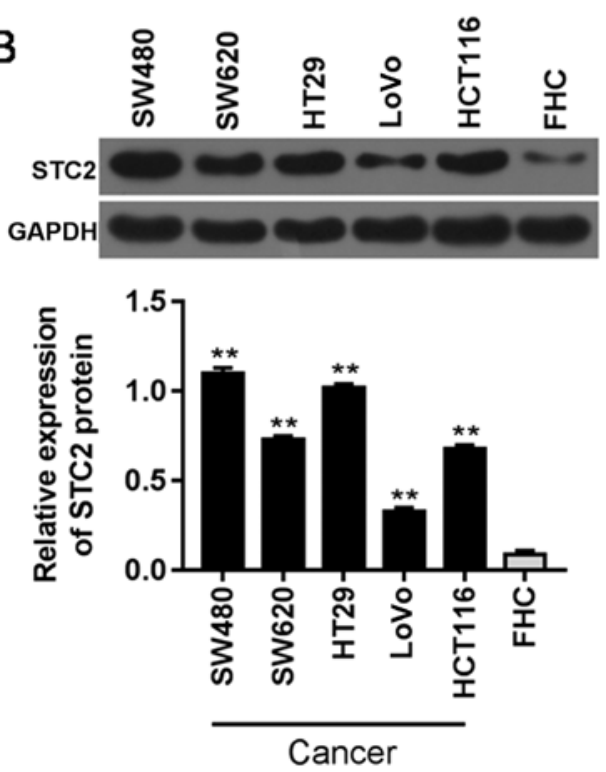

Figure 1. STC2 is highly expressed in CRC cell lines. (A) Quantitative real-time polymerase chain reaction (qPCR) was used to detect the mRNA level of STC2 in CRC cell lines. (B) The protein level of STC2 in CRC cells lines was assessed by western blot analysis. All data are expressed as means \pm SEM. ${ }^{* *} \mathrm{P}<0.01$ vs. the FHC cell line. STC2, stanniocalcin 2; CRC, colorectal cancer.

MMP-9 (Fig. 3E) were downregulated in the siSTC2 group, compared to control group.

$\beta$-catenin is suppressed by siCST2, and SB216763 treatment reverses this effect. In the present study, the expression of $\beta$-catenin was significantly decreased by siSTC 2 at the mRNA (Fig. 4A) and protein level (Fig. 4B). SB216763 (10 $\mu \mathrm{M})$, a Wnt activator, reversed the inhibitory effect of siSTC2 on $\beta$-catenin at the mRNA (Fig. 4C) and protein levels (Fig. 4D), and it also reversed the inhibitory effect of siSTC2 on cell proliferation (Fig. 4E).

\section{Discussion}

One of the most common malignancies in the clinic is colon cancer, the incidence of which is the third highest worldwide (21). It is highly important to identify new colorectal cancer (CRC) treatment targets. It has been reported that stanniocalcin 2 (STC2) is involved in the progression of various types of cancer, such as gastric and breast cancer $(22,23)$. The differential expression levels of $S T C 2$ have certain guiding significance for the prediction, metastasis and prognosis of various malignant tumors (24). Studies have shown that STC2 is involved in the development of CRC $(25,26)$. However, its mechanism of action is not well understood. Therefore, the present study aimed to further explore the mechanism of action of STC2 in CRC.

Studies have found that the expression level of STC2 in CRC patients is higher than that in normal tissues, and that the expression level of $S T C 2$ is related to tumor size and pathological grade $(25,27,28)$. In the present study, it was demonstrated that STC2 was obviously increased in CRC cell lines. The results indicated that $S T C 2$ may play a vital role in the occurrence and development of CRC. Studies have shown that abnormal proliferation, invasion and migration of tumor cells are common conditions in malignant tumors (29-32). Therefore, the ability of tumor invasion and migration is a detrimental biological feature of malignant tumors, and it is also the most prominent clinical manifestation of malignant tumors (33). It has been found that overexpression of STC2 promotes CRC tumorigenesis by activating the AKT/ERK signaling pathway (26). In the present study, we found that silencing of STC2 reduced the cell viability and the migration and invasion abilities, when compared to the control or NC group. These results suggested that STC2 silencing may inhibit the progression of CRC. One study has shown that epithelial-mesenchymal transition (EMT) plays a vital role in tumor invasion and migration (34). Therefore, we explored the effect of STC2 on EMT.

Previous studies on EMT have focused on cancer metastasis profiles $(35,36)$. In fact, the progression of adenocarcinoma from normal intestinal mucosa to adenoma (adenoma mucosa) and eventually to CRC is closely correlated with the EMT process, and the expression changes in a series of genes, such as E-cadherin and vimentin $(37,38)$. MMPs are a group of $\mathrm{Zn}^{2+}$-dependent endopeptidase that can degrade the extracellular matrix (ECM), and promote tumor invasion and migration, proliferation, differentiation and apoptosis of tumor cells (39). Degradation of the extracellular matrix mainly involves the matrix metalloproteinase family, particularly $M M P-2$ and $M M P-9$ (40-42). It has been reported that $M M P-2$ and $M M P-9$ are vital for the metastasis of CRC (43). We hypothesized that knockdown of STC2 would inhibit EMT. Therefore, we investigated the biomarkers of human colon mucosal epithelial cells. Chen et al found that STC2 overexpression could promote the occurrence of EMT in CRC in vitro and in vivo (26). Similarly, we found that silencing of STC2 upregulated E-cadherin expression and downregulated vimentin and MMP-2/-9 expression. Our findings confirmed that the EMT process mediated by $S T C 2$ was associated with the occurrence and development of colon cancer.

Studies have shown that the main signaling pathways involved in the process of EMT are the Wnt $/ \beta$-catenin signaling pathway $(44,45)$. As the $\mathrm{Wnt} / \beta$-catenin signaling pathway is widely involved in cell proliferation, differentiation and metabolism (46), we explored the STC2-mediated $\mathrm{Wnt} / \beta$-catenin molecular signaling pathway and found that the expression of $\beta$-catenin was decreased in the STC2-silenced SW480 cells. $\beta$-catenin is a central molecule of the Wnt signaling pathway. In the presence of Wnt signal stimulation, 

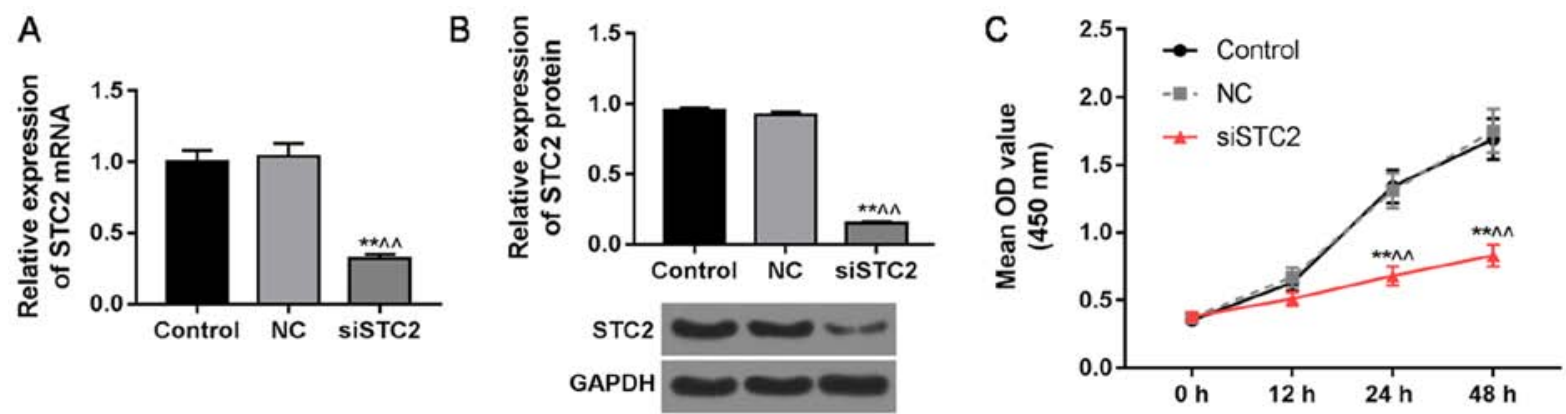

D
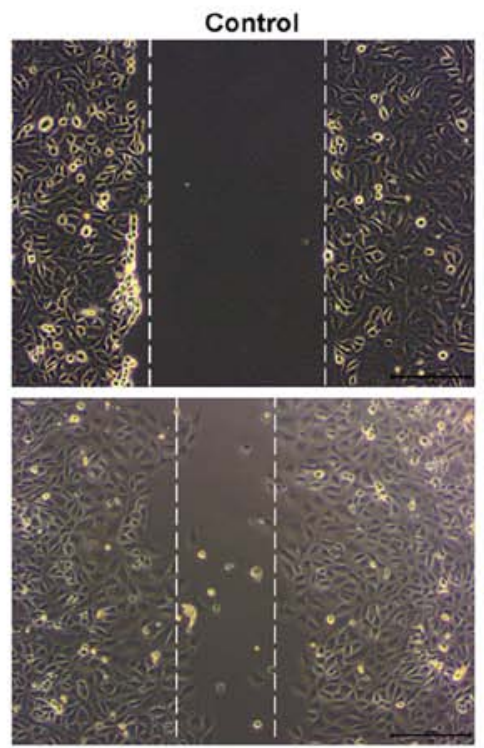

E

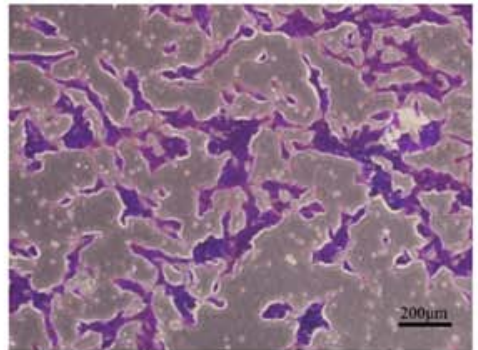

$\mathrm{F}$

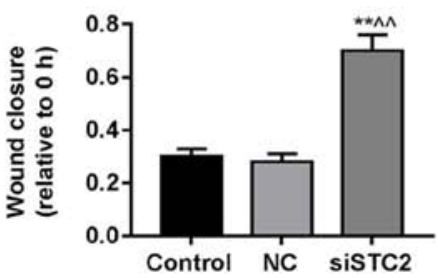

NC
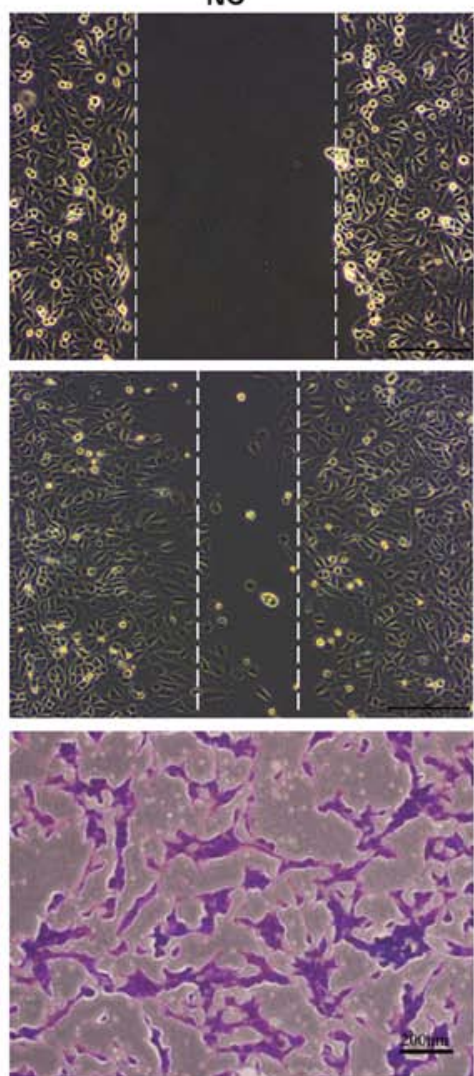

G

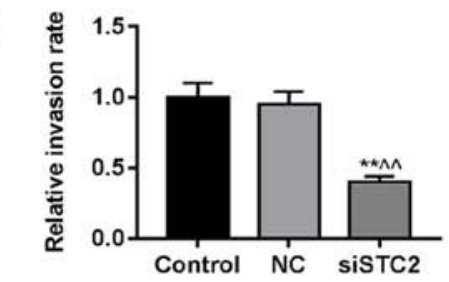

Figure 2. Silencing of STC2 displays an anticancer effect on CRC SW480 cells. (A) Quantitative real-time polymerase chain reaction (qPCR) and (B) western blot analysis were used to evaluate the efficiency of siSTC2 transfection. (C) The cell viability was identified by CCK-8 assay. The migration (D) and invasive (E) abilities were assessed by wound healing and Transwell assays. (F) The relative wound closure distance in the control, NC and siSTC2 groups. (G) The invasion rate of the control, $\mathrm{NC}$ and siSTC2 groups. All data are expressed as means \pm SEM. ${ }^{* *} \mathrm{P}<0.01$ vs. control; ${ }^{\wedge} \mathrm{P}<0.01$ vs. NC. STC2, stanniocalcin 2 ; CCK-8, Cell Counting Kit-8.

Fratl mediates glycogen synthetase kinase $3 \beta$ (GSK-3 $\beta$ ) dissociation from Axin, and prevents the phosphorylation of $\beta$-catenin. $\beta$-catenin is not degraded and accumulates in the cytoplasm. Inhibition of the Wnt/ $\beta$-catenin signaling pathway in colon cancer has been found to alleviate the degree of deterioration of colon cancer (47-49). In the present study, with the activation of the $\mathrm{Wnt} / \beta$-catenin signal pathway, the Wnt activator SB2617763 was found to reverse the inhibitory effect of siSTC2 on Wnt/ $/$-catenin and cell proliferation. SB216763 has been shown to specifically inhibit GSK-3 $\alpha$ and GSK-3 $\beta$, thereby increasing the level of dephosphorylation (active) of $\beta$-catenin $(50,51)$. Briefly, these findings suggest that $\mathrm{Wnt} / \beta$-catenin may be involved in the regulation of CRC following silencing of STC2.

In conclusion, it was demonstrated that STC2 was highly expressed in CRC cell lines, particularly SW480 cells. STC2 

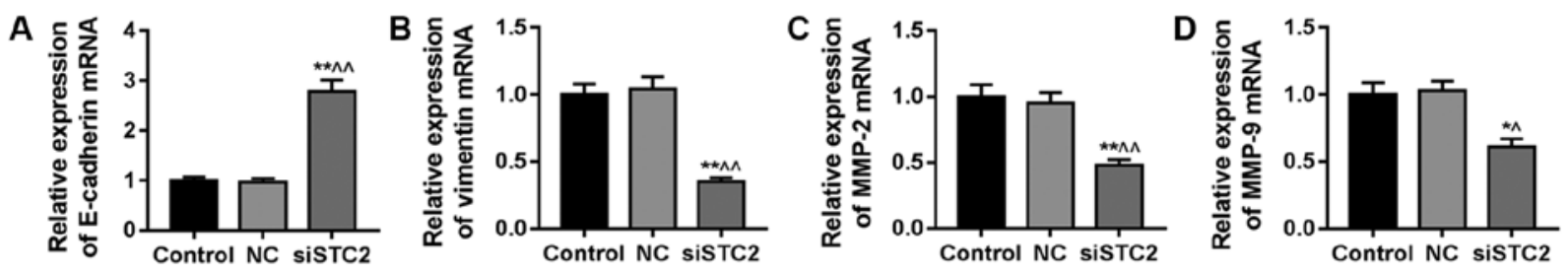

E
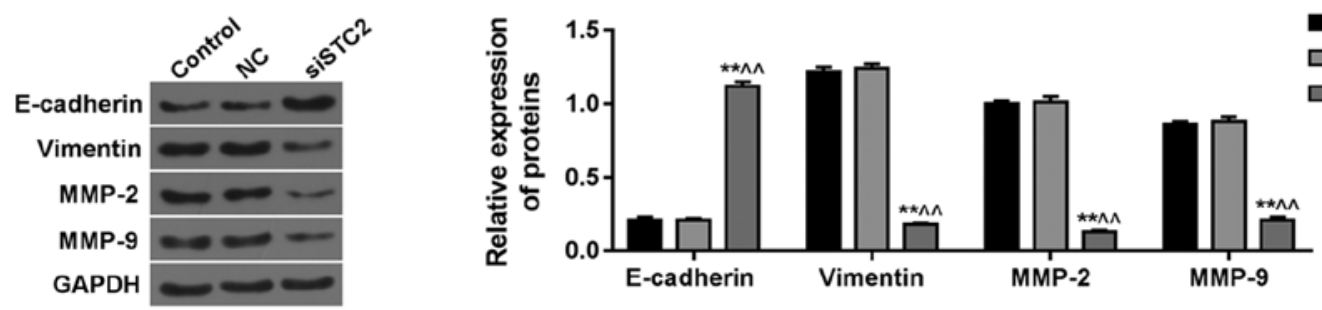

Figure 3. EMT and MMP-2/-9 are suppressed by siSCT2. (A) E-cadherin was increased, while (B) vimentin, (C) $M M P-2$ and (D) $M M P-9$ were decreased in the siSTC2 group, compared to control or NC group as detected by quantitative real-time polymerase chain reaction (qPCR). (E) The proteins levels of E-cadherin, vimentin, MMP-2 and MMP-9 were assessed by normalization to GAPDH. All data are expressed as means \pm SEM. ${ }^{*} \mathrm{P}<0.05,{ }^{* *} \mathrm{P}<0.01$ vs. control; ${ }^{\wedge} \mathrm{P}<0.05$, ${ }^{\wedge} \mathrm{P}<0.01$ vs. NC. EMT, epithelial-mesenchymal transition.

A

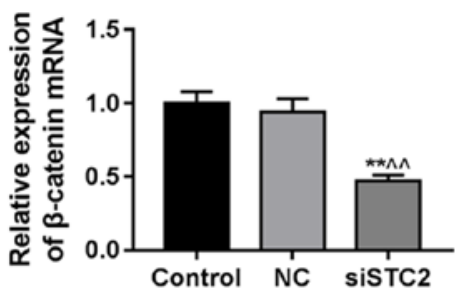

C

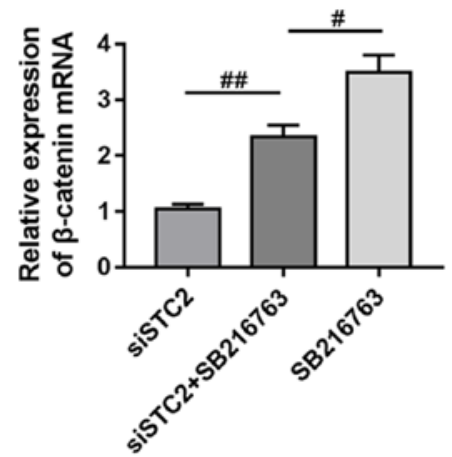

B

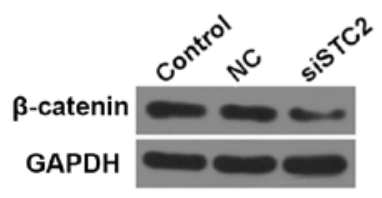

D

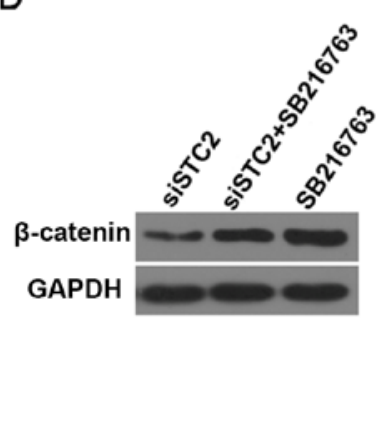

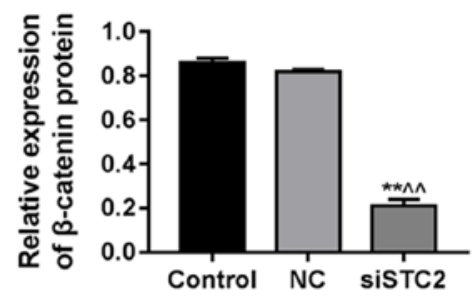

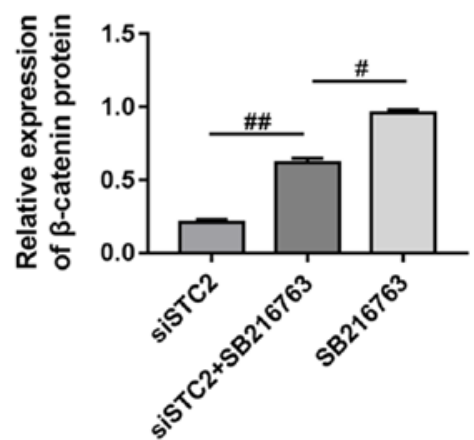

E

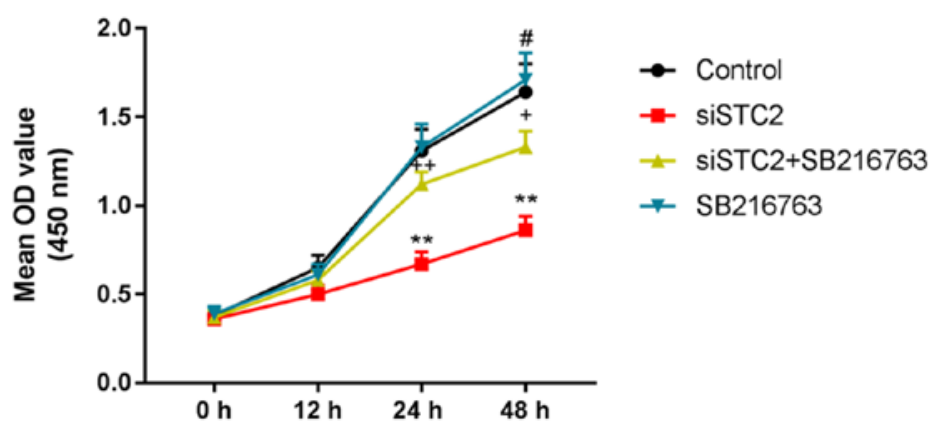

Figure 4. Wnt/ $\beta$-catenin is suppressed by siCST2, and SB216763 reverses the inhibitory effect of siSTC2. $\beta$-catenin was tested by quantitative real-time polymerase chain reaction (qPCR) and western blot analysis at the (A) mRNA and (B) protein levels. SB216763, a Wnt activator, reversed the inhibitory effect of siSTC2 on the Wnt/ $\beta$-catenin pathway at the (C) mRNA and (D) protein levels. (E) SB216763 reversed the inhibitory effect of siSTC2 on cell proliferation. All data are expressed as means \pm SEM. ${ }^{* *} \mathrm{P}<0.01$ vs. control; ${ }^{\wedge} \mathrm{P}<0.01$ vs. NC; ${ }^{*} \mathrm{P}<0.05$ vs. $\operatorname{siSTC} 2+\mathrm{SB} 216763 ;{ }^{\# \#} \mathrm{P}<0.01$ vs. siSTC2; ${ }^{+} \mathrm{P}<0.05,{ }^{++} \mathrm{P}<0.01$ vs. siSTC2

silencing inhibited cell viability, invasion and migration, compared to the control cells. Meanwhile, E-cadherin was increased, while vimentin, $M M P-2$ and $M M P-9$ were decreased in the CRC cells by siSTC2. Unsurprisingly, $\beta$-catenin was 
suppressed by siSTC2, however, SB216763 reversed the level of $\beta$-catenin. Taken together, these data showed that siSTC2 treatment conferred a strong protective effect on CRC. This study suggests that STC2 silencing suppresses the migration of CRC cells and the occurrence of EMT. In addition, the effect of $S T C 2$ on CRC may be related to the $\mathrm{Wnt} / \beta$-catenin signaling pathway. These results provide novel insight into the identification of targeted therapeutic strategies for CRC. However, the present study also has some limitations. Due to the limited experimental funds, we only explored the effect of STC2 on the proliferation, migration and invasion of the CRC SW480 cell line. Whether or not STC2 has the same effect on other CRC cell lines remains to be studied, and we will further conduct gain-of-function experiments in regards to STC2 in future studies. In addition, it is necessary to investigate the role of the Wnt/ $\beta$-catenin pathway in the STC2-mediated effects, so as to better understand the mechanism of STC2 in CRC.

\section{Acknowledgements}

Not applicable.

\section{Funding}

The present study was supported by the Zhejiang Provincial Traditional Chinese Medicine Science Research Foundation (grant no. 2016ZB037).

\section{Availability of data and materials}

The analyzed data sets generated during the study are available from the corresponding author on reasonable request.

\section{Authors' contributions}

QL substantially contributed to the conception and design of the study. XZ and ZF acquired the data, analyzed and interpreted the data. QL and ZP drafted the manuscript or critically revised it for important intellectual content. All authors read and approved the manuscript and agree to be accountable for all aspects of the research in ensuring that the accuracy or integrity of any part of the work are appropriately investigated and resolved.

\section{Ethics approval and consent to participate}

All procedures performed in studies involving human participants were in accordance with the ethical standards of the institutional and/or national research committee and with the 1964 Helsinki declaration and its later amendments or comparable ethical standards. No human or animals were involved in this research.

\section{Patient consent for publication}

Not applicable.

\section{Competing interests}

The authors declare that they have no competing interests.

\section{References}

1. Chen W, Zheng R, Baade PD, Zhang S, Zeng H, Bray F, Jemal A, $\mathrm{Yu}$ XQ and He J: Cancer statistics in China, 2015. CA Cancer J Clin 66: 115-132, 2016.

2. Noreen F, Röösli M, Gaj P, Pietrzak J, Weis S, Urfer P, Regula J, Schär P and Truninger K: Modulation of age- and cancer-associated DNA methylation change in the healthy colon by aspirin and lifestyle. J Natl Cancer Inst 106: pii: dju161, 2014.

3. Pelser C, Arem H, Pfeiffer RM, Elena JW, Alfano CM, Hollenbeck AR and Park Y: Prediagnostic lifestyle factors and survival after colon and rectal cancer diagnosis in the National Institutes of Health (NIH)-AARP diet and health study. Cancer 120: 1540-1547, 2014.

4. Huang W, Liu Z, Zhou G, Tian A and Sun N: Magnetic gold nanoparticle-mediated small interference RNA silencing Bag-1 gene for colon cancer therapy. Oncol Rep 35: 978-984, 2016.

5. Hay ED: The mesenchymal cell, its role in the embryo, and the remarkable signaling mechanisms that create it. Dev Dyn 233: 706-720, 2005 .

6. Zhao JH, Luo Y, Jiang YG, He DL and Wu CT: Knockdown of $\beta$-catenin through shRNA cause a reversal of EMT and metastatic phenotypes induced by HIF-1 $\alpha$. Cancer Invest 29: 377-382, 2011.

7. Wang Y, Shi J, Chai K, Ying X and Zhou BP: The role of Snail in EMT and tumorigenesis. Curr Cancer Drug Targets 13: 963-972, 2013.

8. Reinacher-Schick A, Baldus SE, Romdhana B, Landsberg S, Zapatka M, Mönig SP, Hölscher AH, Dienes HP, Schmiegel W and Schwarte-Waldhoff I: Loss of Smad4 correlates with loss of the invasion suppressor E-cadherin in advanced colorectal carcinomas. J Pathol 202: 412-420, 2004.

9. Wu CY, Tsai YP, Wu MZ, Teng SC and Wu KJ: Epigenetic reprogramming and post-transcriptional regulation during the epithelial-mesenchymal transition. Trends Genet 28: 454-463, 2012.

10. Zhang Z, Yao L, Yang J, Wang Z and Du G: PI3K/Akt and HIF-1 signaling pathway in hypoxiaischemia (Review). Mol Med Rep 18: 3547-3554, 2018.

11. Miyoshi K and Hennighausen L: Beta-catenin: A transforming actor on many stages. Breast Cancer Res 5: 63-68, 2003.

12. Maruyama K, Ochiai A, Akimoto S, Nakamura S, Baba S, Moriya Y and Hirohashi S: Cytoplasmic beta-catenin accumulation as a predictor of hematogenous metastasis in human colorectal cancer. Oncology 59: 302-309, 2000.

13. Zhou W, Li Y, Gou S, Xiong J, Wu H, Wang C, Yan H and Liu T: MiR-744 increases tumorigenicity of pancreatic cancer by activating Wnt/ $\beta$-catenin pathway. Oncotarget 6: 37557-37569, 2015.

14. Margariti A, Zampetaki A, Xiao Q, Zhou B, Karamariti E, Martin D, Yin X, Mayr M, Li H, Zhang Z, et al: Histone deacetylase 7 controls endothelial cell growth through modulation of beta-catenin. Circ Res 106: 1202-1211, 2010.

15. Jia S, Qu T, Wang X, Feng M, Yang Y, Feng X, Ma R, Li W, Hu Y, Feng Y, et al: KIAA1199 promotes migration and invasion by Wnt/ $\beta$-catenin pathway and MMPs mediated EMT progression and serves as a poor prognosis marker in gastric cancer. PLoS One 12: e0175058, 2017

16. Chen WN and Zhu GJ: Progress in the research of stanniocalcin. Sheng Li Ke Xue Jin Zhan 39: 225-228, 2008 (In Chinese).

17. Chang AC, Jellinek DA and Reddel RR: Mammalian stanniocalcins and cancer. Endocr Relat Cancer 10: 359-373, 2003.

18. Yeung BH, Law AY and Wong CK: Evolution and roles of stanniocalcin. Mol Cell Endocrinol 349: 272-280, 2012.

19. Livak KJ and Schmittgen TD: Analysis of relative gene expression data using real-time quantitative PCR and the 2(-Delta Delta $\mathrm{C}(\mathrm{T})$ ) method. Methods 25: 402-408, 2001.

20. Karagiannis GS, Berk A, Dimitromanolakis A and Diamandis EP: Enrichment map profiling of the cancer invasion front suggests regulation of colorectal cancer progression by the bone morphogenetic protein antagonist, gremlin-1. Mol Oncol 7: 826-839, 2013.

21. Jemal A, Siegel R, Xu J and Ward E: Cancer statistics, 2010. CA Cancer J Clin 60: 277-300, 2010.

22. Arigami T, Uenosono $Y$, Ishigami $S$, Yanagita $S$, Hagihara $T$, Haraguchi N, Matsushita D, Hirahara T, Okumura $H$, Uchikado Y, et al: Clinical significance of stanniocalcin 2 expression as a predictor of tumor progression in gastric cancer. Oncol Rep 30: 2838-2844, 2013. 
23. Coulson-Gilmer C, Humphries MP, Sundara Rajan S, Droop A, Jackson S, Condon A, Cserni G, Jordan LB, Jones LJ, Kanthan R, et al: Stanniocalcin 2 expression is associated with a favourable outcome in male breast cancer. J Pathol Clin Res 4: 241-249, 2018.

24. Parris TZ, Kovacs A, Aziz L, Hajizadeh S, Nemes S, Semaan M, Forssell-Aronsson E, Karlsson P and Helou K: Additive effect of the AZGP1, PIP, S100A8 and UBE2C molecular biomarkers improves outcome prediction in breast carcinoma. Int J Cancer 134: $1617-1629,2014$

25. Hashemzadeh S, Arabzadeh AA, Estiar MA, Sakhinia M, Mesbahi N, Emrahi L, Ghojazadeh M and Sakhinia E: Clinical utility of measuring expression levels of Stanniocalcin 2 in patients with colorectal cancer. Med Oncol 31: 237, 2014

26. Chen B, Zeng X, He Y, Wang X, Liang Z, Liu J, Zhang P, Zhu H, $\mathrm{Xu} \mathrm{N}$ and Liang S: STC2 promotes the epithelial-mesenchymal transition of colorectal cancer cells through AKT-ERK signaling pathways. Oncotarget 7: 71400-71416, 2016.

27. Ieta K, Tanaka F, Yokobori $\mathrm{T}$, Kita $\mathrm{Y}$, Haraguchi $\mathrm{N}$, Mimori K, Kato H, Asao T, Inoue $\mathrm{H}$, Kuwano $\mathrm{H}$ and Mori M: Clinicopathological significance of stanniocalcin 2 gene expression in colorectal cancer. Int J Cancer 125: 926-931, 2009.

28. Miyazaki S, Kikuchi H, Iino I, Uehara T, Setoguchi T, Fujita T, Hiramatsu Y, Ohta M, Kamiya K, Kitagawa K, et al: Anti-VEGF antibody therapy induces tumor hypoxia and stanniocalcin 2 expression and potentiates growth of human colon cancer xenografts. Int J Cancer 135: 295-307, 2014.

29. Leve F, Peres-Moreira RJ, Binato R, Abdelhay E and MorgadoDiaz JA: LPA Induces colon cancer cell proliferation through a cooperation between the ROCK and STAT-3 pathways. PLoS One 10: e0139094, 2015

30. Yoshida GJ: Metabolic reprogramming: The emerging concept and associated therapeutic strategies. J Exp Clin Cancer Res 34 111,2015

31. Wang $J$ and Sun $X$ : MicroRNA-375 inhibits the proliferation, migration and invasion of kidney cancer cells by triggering apoptosis and modulation of PDK1 expression. Environ Toxicol Pharmacol 62: 227-233, 2018.

32. Chu GC and Chung LW: RANK-mediated signaling network and cancer metastasis. Cancer Metastasis Rev 33: 497-509, 2014.

33. Probst OC, Karayel E, Schida N, Nimmerfall E, Hehenberger E, Puxbaum V and Mach L: The mannose 6-phosphate-binding sites of M6P/IGF2R determine its capacity to suppress matrix invasion by squamous cell carcinoma cells. Biochem $\mathrm{J} 451$ : 91-99, 2013.

34. Kitamura T and Taketo MM: Keeping out the bad guys: Gateway to cellular target therapy. Cancer Res 67: 10099-10102, 2007.

35. Škovierová $H$, Okajčeková T, Strnádel J, Vidomanová E and Halašová E: Molecular regulation of epithelial-to-mesenchymal transition in tumorigenesis (Review). Int J Mol Med 41: 1187-1200, 2018

36. Gurzu S, Silveanu C, Fetyko A, Butiurca V, Kovacs Z and Jung I: Systematic review of the old and new concepts in the epithelial-mesenchymal transition of colorectal cancer. World J Gastroenterol 22: 6764-6775, 2016.

37. Vincan E, Brabletz T, Faux MC and Ramsay RG: A human three-dimensional cell line model allows the study of dynamic and reversible epithelial-mesenchymal and mesenchymal-epithelial transition that underpins colorectal carcinogenesis. Cells Tissues Organs 185: 20-28, 2007.

38. Chen X, Halberg RB, Burch RP and Dove WF: Intestinal adenomagenesis involves core molecular signatures of the epithelial-mesenchymal transition. J Mol Histol 39: 283-294, 2008
39. Han X, Fang X, Lou X, Hua D, Ding W, Foltz G, Hood L, Yuan Y and Lin B: Silencing SOX2 induced mesenchymal-epithelial transition and its expression predicts liver and lymph node metastasis of CRC patients. PLoS One 7: e41335, 2012.

40. He Q, Li H, Meng F, Sun X, Feng X, Chen J, Li L and Liu J: Methionine sulfoxide reductase B1 regulates hepatocellular carcinoma cell proliferation and invasion via the mitogen-activated protein kinase pathway and epithelial-mesenchymal transition. Oxid Med Cell Longev 2018: 5287971, 2018.

41. Ryu ES, Kim MJ, Shin HS, Jang YH, Choi HS, Jo I, Johnson RJ and Kang DH: Uric acid-induced phenotypic transition of renal tubular cells as a novel mechanism of chronic kidney disease. Am J Physiol Renal Physiol 304: F471-F480, 2013.

42. Lemieux E, Bergeron S, Durand V, Asselin C, Saucier C and Rivard N: Constitutively active MEK1 is sufficient to induce epithelial-to-mesenchymal transition in intestinal epithelial cells and to promote tumor invasion and metastasis. Int J Cancer 125: $1575-1586,2009$

43. Park KS, Kim SJ, Kim KH and Kim JC: Clinical characteristics of TIMP2, MMP2, and MMP9 gene polymorphisms in colorectal cancer. J Gastroenterol Hepatol 26: 391-397, 2011.

44. Fu W, Tao T, Qi M, Wang L, Hu J, Li X, Xing N, Du R and Han B: MicroRNA-132/212 upregulation inhibits TGF- $\beta$-mediated epithelial-mesenchymal transition of prostate cancer cells by targeting SOX4. Prostate 76: 1560-1570, 2016.

45. Zhang JX, Zhai JF, Yang XT and Wang J: MicroRNA-132 inhibits migration, invasion and epithelial-mesenchymal transition by regulating TGF $\beta 1 / \mathrm{Smad} 2$ in human non-small cell lung cancer. Eur Rev Med Pharmacol Sci 20: 3793-3801, 2016.

46. Teichroeb JH, Kim J and Betts DH: The role of telomeres and telomerase reverse transcriptase isoforms in pluripotency induction and maintenance. RNA Biol 13: 707-719, 2016.

47. Kim HJ, Moon SJ, Kim SH, Heo K and Kim JH: DBC1 regulates Wnt/ $\beta$-catenin-mediated expression of MACC1, a key regulator of cancer progression, in colon cancer. Cell Death Dis 9: 831, 2018.

48. Li X, Hu W, Zhou J, Huang Y, Peng J, Yuan Y, Yu J and Zheng S: CLCA1 suppresses colorectal cancer aggressiveness via inhibition of the Wnt/beta-catenin signaling pathway. Cell Commun Signal 15: 38, 2017.

49. Han X, Zheng J, Wang Y and Gao Z: miRNA-29a inhibits colon cancer growth by regulation of the PTEN/Akt/GSK3 $\beta$ and Wnt/ $\beta$-catenin signaling pathways. Oncol Lett 16: 2638-2644, 2018.

50. Zhang Y, Seid K, Obermayr F, Just L and Neckel PH: Activation of Wnt signaling increases numbers of enteric neurons derived from neonatal mouse and human progenitor cells. Gastroenterology 153 : 154-165.e9, 2017

51. Mao D, Qiao L, Lu H and Feng Y: B-cell translocation gene 3 overexpression inhibits proliferation and invasion of colorectal cancer SW480 cells via Wnt/ $\beta$-catenin signaling pathway. Neoplasma 63: 705-716, 2016.

This work is licensed under a Creative Commons Attribution-NonCommercial-NoDerivatives 4.0 International (CC BY-NC-ND 4.0) License. 